\title{
Ensino do português no contexto do Mercosul: revisitando o passado para compreender o presente e planejar futuras ações ${ }^{1}$
}

\author{
Patricia Maria Campos de ALMEIDA $A^{2}$ \\ Universidade Federal do Rio de Janeiro \\ patricia.mca@hotmail.com \\ Andrea Lima BELFORT DUARTE ${ }^{3}$ \\ Universidade Federal Rio de Janeiro \\ decabelfort@hotmail.com
}

\section{Resumo}

A fim de identificar medidas adotadas pelo governo brasileiro para fomentar a difusão da variante brasileira da língua portuguesa, bem como da cultura brasileira no âmbito do Mercosul, empreendemos esta pesquisa cujos propósitos foram: (1) revisitar as políticas adotadas pelo governo brasileiro para o caso em tela; (2) identificar grupos de demanda para o português como LE/L2; (3) apresentar dados que auxiliassem em uma análise da situação atual do ensino de português para os parceiros do Mercosul. Assim, apresentamos resultados de investigação de base documental, com o intuito de contribuir criticamente para uma reflexão sobre a difusão da língua portuguesa e da cultura brasileira, bem como sobre futuras ações para o ensino do português no Mercosul. Os resultados de nossa investigação apresentam propostas claras no tocante ao ensinoaprendizado do português pelos parceiros do Mercosul. Ressaltamos,

1 Uma versão preliminar deste trabalho foi apresentada durante o Congresso da Associação Internacional de Língua Portuguesa, realizado em 2010, na Universidade Federal Fluminense.

2 Professora Doutora do Departamento de Letras Vernáculas, Setor de Português Língua Estrangeira, da Faculdade de Letras da UFRJ.

3 Professora Mestre do Departamento de Letras Vernáculas, Setor de Português Língua Estrangeira, da Faculdade de Letras da UFRJ, doutoranda pela Universidade Federal Fluminense. 
ainda, a importância do Brasil como país que acolhe interessados em desenvolver estudos e atividades relacionadas ao trabalho. Dessa forma, verificamos a evidente necessidade de investimentos mais maciços em formação docente e pesquisas, além de incentivos para publicações teóricas e de materiais didáticos.

Palavras-chave: português língua estrangeira; Mercosul; política linguística.

\section{Abstract}

In order to identify policies adopted by the Brazilian government to foster the Brazilian variant of the Portuguese language and to promote the country's culture within the MERCOSUR, our research is focused on: (1) reviewing the policies adopted by the government of Brazil regarding the mentioned issues; (2) identifying groups interested in Portuguese as a second or foreign language; (3) presenting data that support the analysis of the current status of teaching Portuguese in MERCOSUR countries. Therefore, we present results of a documental research for the issues above, with the objective of contributing towards the reflection on the Portuguese language and the Brazilian culture, as well as future proposals regarding teaching/learning Portuguese in the MERCOSUR. We also highlight the importance of Brazil as a country that welcomes immigrants interested in developing studies, research and activities related to several careers. In view of this we have verified the need for substantial investments in teacher qualification, theoretical and scientific publications as well as hands-on learning materials.

Keywords: Portuguese for foreigners; MERCOSUR; language policy.

\section{Introdução}

A construção de uma integração internacional, a exemplo do que foi proposto para o bloco do Mercado Comum do Sul (Mercosul), tem as questões linguística e cultural como elementos fundamentais para o seu sucesso. Desse modo, é preciso, para uma integração que se queira plena, que os países participantes do bloco estabeleçam políticas claras para difundir a importância de seu idioma para os parceiros regionais. 
Ainda com relação ao Mercosul, vale ressaltar que o Brasil é citado, com certa recorrência, como a potência regional de maior destaque dentre todas as que integram o bloco econômico citado. Isso se deve, certamente, ao desempenho econômico do Brasil quando comparado ao desempenho dos demais países nos últimos anos.

A importância econômica do Brasil dentro do bloco pode ser confirmada com a análise de alguns indicadores, tais como: produto interno bruto $(\mathrm{PIB})^{4}$ dos países que integram o bloco, volume de exportações (em dólar); população (mercado consumidor potencial) e participação dos países no PIB do Mercosul.

Quadro 1: PIB (PPC), exportações e população dos países do Mercosul $^{5}$

\begin{tabular}{|l|l|l|l|}
\hline País & PIB (PPC) & Exportações & População \\
\hline Brasil & \$1.552.542 milhões & \$118.000 milhões & 184,2 milhões \\
\hline Argentina & \$516.951 milhões & \$33.700 milhões & 39,1 milhões \\
\hline Venezuela & \$153.331 milhões & \$35.840 milhões & 24 milhões \\
\hline Uruguai & \$32.885 milhões & \$2.200 milhões & 3,4 milhões \\
\hline Paraguai & \$29.014 milhões & \$2.940 milhões & 6,2 milhões \\
\hline
\end{tabular}

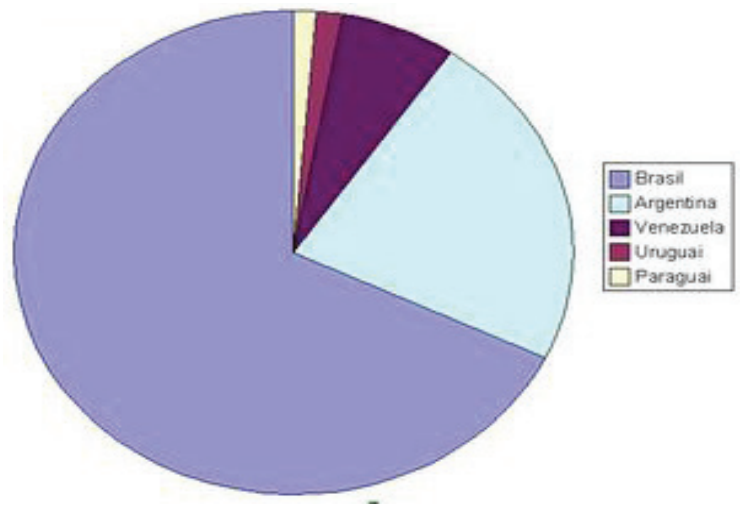

Figura 1: Participação dos países no PIB (PPC) do Mercosul ${ }^{6}$

4 Valor estimado do PIB dos países membros do Mercosul utilizando o critério de Paridade do Poder de Compra (PPC). A unidade monetária utilizada é o dólar internacional. Dados do Banco Mundial.

5 O Quadro 1 está disponível para consulta em: <http://www.classificadosmercosul.com.br/ mercosul atual.htm>.

6 Figura 1 está disponível para consulta em: $<$ http://www.classificadosmercosul.com.br/mercosul_atual.htm $>$. 
Com esses dados, verificamos que, de fato, o Brasil assume uma liderança econômica, atraindo, portanto, a atenção de interessados em estabelecer relações comerciais com nosso país. Do ponto de vista do ensino-aprendizagem do português, espera-se que o estabelecimento de novas relações comerciais signifique também um desejo de aprender a língua falada no Brasil e de conhecer aspectos da cultura brasileira.

Nesse sentido, podemos nos perguntar o que tem sido feito pelo governo brasileiro para favorecer a divulgação de seu idioma e cultura em âmbito internacional, considerando-se principalmente os países do Mercosul. A fim de buscar resposta para essa pergunta, revisitamos um estudo anterior sobre o ensino de português como segunda língua para os parceiros do Mercosul (ALMEIDA; ESPÍRITO SANTO JR., 2000)7 com o propósito de verificar os avanços empreendidos nessa direção. Vale lembrar que, naquela época, especialistas viam com muito entusiasmo os rumos que tomava o Mercosul e vislumbravam, então, inúmeras oportunidades para o incremento do ensino do português para as nações vizinhas.

Uma década após, voltamos nossa atenção mais uma vez para o contexto do Mercosul, agora com os seguintes objetivos:

1. revisitar as medidas adotadas pelo governo brasileiro - com ênfase na discussão das mais recentes - para fomentar, no âmbito do Mercosul, a difusão da variante brasileira da língua portuguesa, bem como a difusão da cultura brasileira;

2. identificar grupos de demanda para o português como LE/L2 $2^{8}$;

3. apresentar dados que auxiliem em uma análise da situação atual do ensino de português para os parceiros do Mercosul.

As fontes utilizadas para a obtenção dos dados apresentados em nossa investigação são documentos divulgados, na maior parte, por órgãos governamentais em meio eletrônico e impresso. Assim,

7 O estudo indicado foi apresentado no Seminário Internacional Mercosul em Debate, realizado em novembro de 2000, no Rio de Janeiro.

8 Os termos LE e L2 foram utilizados para indicar, respectivamente, o ensino de português em situação de não imersão e o ensino em situação imersão. 
trazemos resultados de uma pesquisa de base documental, cujo objetivo é contribuir de forma crítica para uma reflexão sobre a difusão da língua portuguesa e da cultura brasileira, bem como sobre futuras ações para o ensino do português no âmbito do Mercosul.

A seguir, retomaremos alguns fatos importantes para a compreensão do processo de constituição do Mercosul. Na sequência, serão apresentadas algumas medidas para a difusão do português do Brasil e da cultura brasileira no bloco citado, tendo em vista o período de 2005 a 2010. Mais adiante, a partir dos dados obtidos junto à Polícia Federal e ao Ministério do Trabalho e Emprego, trataremos dos grupos de demanda para ensino-aprendizagem do português, considerando, mais uma vez, o Mercosul.

\section{O Mercado Comum do Sul}

A título de estabelecer um panorama político para as questões que vamos focalizar, vale lembrar que no dia 26 de março de 1991, ao assinarem o Tratado de Assunção, a República Argentina, a República Federativa do Brasil, a República do Paraguai e a República Oriental do Uruguai formalizaram a intenção de constituir um mercado comum, denominado, então, Mercado Comum do Sul (Mercosul). Os objetivos mais gerais desse mercado são os seguintes: (1) consolidar a integração política, econômica e social entre os países que integram o bloco; (2) fortalecer os vínculos entre os cidadãos dos países membros a fim de melhorar sua qualidade de vida; (3) incorporar o setor produtivo para aumentar sua competitividade em nível regional e internacional. $\mathrm{O}$ mercado comum prevê a livre circulação de bens, serviços e fatores produtivos, o estabelecimento de uma tarifa externa comum, a adoção de uma política comercial comum, a coordenação de políticas macroeconômicas e setoriais e a harmonização de legislações nacionais para alcançar o fortalecimento do processo de integração. 
Com a intenção de fortalecer as relações com os demais países da América Latina - já que integram o bloco apenas Brasil, Argentina, Paraguai e Uruguai - o Mercosul assinou acordos de livre comércio com o Estado Plurinacional da Bolívia (1996), com a República do Chile (1996), com a República do Peru (2003), com a República da Colômbia (2004), com a República do Equador (2004) e com a República Bolivariana da Venezuela (2004), países que, então, passaram a ser denominados Estados Associados. Considerando ainda a consolidação do processo de integração latino-americana, em 4 de julho de 2006, foi aprovado o Protocolo de Adesão da República Bolivariana da Venezuela ao Mercosul, dando início a um processo de transformação de Estado Associado em Estado Parte do Mercosul (Cartilha do Cidadão do Mercosul, edição 2010).

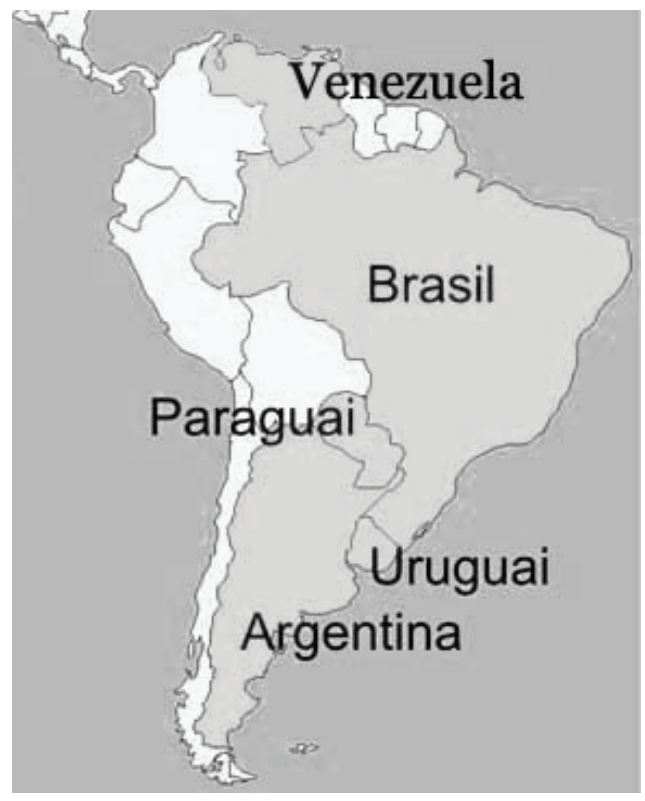

Figura 2: Constituição do Mercosul (Membros e Estado Parte)

No panorama político que estamos delineando, vale lembrar mais uma vez que o Brasil sempre possuiu destacada importância como a maior economia da América Latina. Assim, o nosso país tem servido como referência político-econômica. Apontar a liderança do Brasil nesse bloco 
parece óbvio e redundante, mas cabe reforçar que uma liderança desprovida de integração não consegue realizar os objetivos traçados, muito menos otimizar os resultados a serem atingidos.

Inseridos como um dos mais importantes elos na construção da integração a que nos referimos anteriormente, está, obviamente, o ensino de idiomas, mais particularmente do português e do espanhol.Isso já se mostrava claro há dez anos. $\mathrm{Na}$ época, apostando, sobretudo, no estabelecimento de potenciais relações comerciais entre os países do bloco, verificou-se, no Brasil, um crescente número de interessados em aprender espanhol e a proliferação de cursos que ofereciam esse idioma para os brasileiros. $\mathrm{Na}$ ocasião, perguntávamos a quantas andava a difusão do português para os demais países do Mercosul e tantos outros mais interessados em aprender nosso idioma e nossa cultura. A pergunta era motivada pelo fato de que não eram observados movimentos mais precisos nesse sentido. A percepção da época era de que o ensino de espanhol no Brasil crescia vertiginosamente, enquanto o ensino do português nos demais países do Mercosul caminhava a passos lentos.

Hoje, depois de transcorrida a década que separa as duas fases desse estudo, revisitamos medidas adotadas pelo governo brasileiro - com ênfase na discussão daquelas mais recentes - para fomentar, no âmbito do Mercosul, a difusão da variante brasileira da língua portuguesa, bem como a difusão da cultura brasileira. Os dados levantados são apresentados a seguir.

\section{Difusão do Português do Brasil e da cultura brasileira no Mercosul}

Conforme mencionado, pretendemos, nesta parte, apresentar algumas das medidas adotadas mais recentemente para incentivar o ensino do português no âmbito do Mercosul. A apresentação das informações relativas a esse tópico seguirá o critério de ordem cronológica 9 .

9 Para compor o levantamento apresentado foram utilizadas fontes primárias disponíveis online em sites institucionais. Essas fontes estão listadas no fim do artigo. 


\section{1. $\operatorname{Em} 2005$}

- Assinatura do protocolo entre o Ministério da Educação, Ciência e Tecnologia da República Argentina e o Ministério da Educação da República Federativa do Brasil para a promoção do ensino do espanhol e do português como segundas línguas. $\mathrm{O}$ protocolo prevê, entre outros aspectos:

a) implementação dos Programas de Formação de Ensino do Espanhol e de Português como Segunda Língua;

b) lançamento do Programa Bilateral de Intercâmbio de Assistentes de Idioma;

c) fomento de Convênios Interinstitucionais entre universidades argentinas e brasileiras para formação conjunta de ofertas acadêmicas, com dupla certificação, para o ensino do espanhol e do português como segunda língua;

d) fomento de associações de empresas editoriais argentinas e brasileiras para a edição de livros de texto destinados para o ensino e a formação de docentes de espanhol e do português;

e) ampliação dos exames para a obtenção dos Certificados de Espanhol Língua e Uso (CELU) e do Certificado de Proficiência da Língua Brasileira para Estrangeiros (CELPE-Bras), nos respectivos países.

- Início do Programa Escola Bilíngue de Fronteira - o Projeto Escola Intercultural Bilíngue de Fronteira (PEIBF) tem por objetivo aproximar estudantes e professores brasileiros de alunos e professores dos países vizinhos, buscando a integração, a quebra de fronteira, além da ampliação das oportunidades do aprendizado da segunda língua. $O$ programa foi criado, nesse ano, por uma ação bilateral Brasil-Argentina.

Thomaz (2010), ao analisar a política linguística do PEIBF, observa que há, na política linguística traçada para o Mercosul, uma subdivisão que contém a política linguística do bloco para a situação específica da região de fronteira. Isso significa que, enquanto a 
política linguística mais geral está vinculada à promoção das línguas oficiais do bloco nos países membros, a política linguística para a região de fronteira prevê a promoção das línguas oficiais como L2.

\subsection{Em 2006}

- É desenvolvido e implementado pelo Setor Educacional do Mercosul (SEM) um Programa de Mobilidade Acadêmica Regional em Cursos Acreditados (Marca). Esse programa atende a duas prioridades do planejamento estratégico do setor: a melhoria da qualidade acadêmica, por meio de sistemas de avaliação e acreditação, e a mobilidade de estudantes, docentes e pesquisadores entre instituições e países. Participam do programa cursos de graduação avaliados e aprovados pelo Sistema de Acreditação Regional de Cursos Universitários do Mercosul (ARCU-SUL) pertencentes a instituições dos países do bloco. No ano de 2006, o Marca envolveu o intercâmbio de 58 alunos entre cursos de Agronomia em 17 instituições acreditadas do Brasil, Argentina, Paraguai Uruguai, Bolívia e Chile. Em 2008, o Marca incorporou cursos de Engenharia e Medicina, envolvendo um total de 44 instituições e mais de 150 estudantes.

\section{3. $\mathrm{Em} 2007$}

Estabelecimento do Programa Executivo Educacional entre o governo da República Federativa do Brasil e o governo da República do Paraguai que prevê, entre outros aspectos:

a) criação de uma licenciatura em língua portuguesa e cultura brasileira;

b) educação intercultural: ensino do idioma português no Paraguai e do idioma espanhol e guarani no Brasil, através do programa intercultural bilíngue e trilingue entre os professores e os alunos do ensino médio e fundamental da região de fronteira; 
c) criação de leitorado de língua portuguesa e literatura brasileira em universidade paraguaia;

d) cooperação entre a Coordenação de Aperfeiçoamento de Pessoal de Nível Superior (Capes) e a Universidade Nacional de Assunção para a criação de licenciatura em língua portuguesa e literatura brasileira (fato noticiado pelo Estadão, em 14 de abril de 2007).

\section{4. $\operatorname{Em} 2009$}

A ministra uruguaia da Educação e Cultura, Maria Simón, anuncia, nesse ano, na XII Conferência Ibero-Americana de Ministros da Cultura, realizada em Portugal, que o país teria, a partir de 2010, o ensino do português como segundo idioma nas escolas públicas ${ }^{10}$.

Ampliação do Programa Escola Bilíngue de Fronteira. Segundo consta em relatório, até 2008 o projeto tinha sido implantado em 14 escolas dos dois países, e em 2009 eram 26 escolas. Escolas públicas de quatro municípios dos estados do Rio Grande do Sul, Mato Grosso do Sul e Roraima, que ficam na divisa com cidades do Uruguai, do Paraguai ou da Venezuela, ingressam, em 2009, no Projeto Escola Intercultural Bilíngue de Fronteira. Conforme dito, iniciou-se esse programa, em 2005, como uma ação bilateral Brasil-Argentina. Em 2009, o projeto amplia sua abrangência e passa a ser uma ação dos países do Mercosul. Os municípios que passaram a participar do projeto no início do ano letivo de 2009 foram Jaguarão-RS, em parceria com Rio Branco (Uruguai); Chuí-RS, com a cidade de Chuy (Uruguai); Ponta Porã-MS, com Pedro Juan Caballero (Paraguai); e Pacaraima-RR, com Santa Elena de Uiarén (Venezuela), conforme exposto na Tabela 1.

10 Fato noticiado pelo jornal Estadão, em 22 de abril de 2009. Disponível em: <http://www.estadao.com. $\mathrm{br} /$ noticias/geral,uruguai-ensinara-portugues-nas-escolas-publicas-a-partir-de-2010,358706,0.htm . 
Tabela 1: Projeto Escola Intercultural Bilíngue de Fronteira (PEIBF): cidades e escolas participantes em $2009^{11}$

\begin{tabular}{|c|c|c|c|c|}
\hline Fronteira & Cidades & $\begin{array}{l}N^{\circ} \text { de } \\
\text { escolas }\end{array}$ & $\begin{array}{l}\mathrm{N}^{\circ} \mathrm{de} \\
\text { turmas }\end{array}$ & Escolas \\
\hline \multirow[t]{13}{*}{$\begin{array}{l}\text { Brasil - } \\
\text { Argentina }\end{array}$} & $\begin{array}{l}\text { Dinisio Cerqueira/ } \\
\text { SC }\end{array}$ & 1 & 8 & EEB Dr. Theodureto de Faria Souto \\
\hline & $\begin{array}{l}\text { Bernardo de } \\
\text { Irigoyen/Corrientes }\end{array}$ & 1 & 10 & Escuela Intercultural Bilingue $\mathrm{N}^{\circ} 1$ \\
\hline & Itaqui/RS & 1 & 4 & EM Otávio Silveira \\
\hline & Alevar/Corrientes & 1 & 4 & Escuela Del Montes (N¹23) \\
\hline & Itaqui/RS & 1 & 8 & EM Vicente Soles \\
\hline & La Cruz/Corrientes & 1 & 8 & $\begin{array}{l}\text { Escuela Gobierno de Tierra Del Fuego } \\
\left(\mathrm{N}^{\circ} 478\right)\end{array}$ \\
\hline & Uruguaiana/RS & 1 & 7 & Escola CAIC \\
\hline & $\begin{array}{l}\text { Paso de los Libres/ } \\
\text { Corrientes }\end{array}$ & 1 & 7 & Escuela Vicente Verón \\
\hline & Foz do Iguaçu/PR & 1 & 7 & EMEF Adele Zanoto Scalco \\
\hline & $\begin{array}{l}\text { Puerto Iguazú/ } \\
\text { Missiones }\end{array}$ & 1 & 7 & Escuela Bilingue Intercultural № 2 \\
\hline & São Borja/RS & 1 & 11 & EMEF Ubaldo Sorrilha da Costa \\
\hline & $\begin{array}{l}\text { Santo Tomé/ } \\
\text { Corrientes }\end{array}$ & 2 & & $\begin{array}{l}\text { Escuela No } 484 \text { Estados Unidos do } \\
\text { Brasil }\end{array}$ \\
\hline & & & & $\begin{array}{l}\text { Escuela No } 554 \text { Josefa Fernandez dos } \\
\text { Santos }\end{array}$ \\
\hline \multirow[t]{2}{*}{$\begin{array}{l}\text { Brasil - } \\
\text { Paraguay }\end{array}$} & PontaPorã/MS & 1 & 6 & EE João Brembatti Calvoso \\
\hline & $\begin{array}{l}\text { Pedro Juan } \\
\text { Caballero/PY }\end{array}$ & 1 & 6 & \\
\hline \multirow[t]{6}{*}{$\begin{array}{l}\text { Brasil - } \\
\text { Uruguay }\end{array}$} & Jaguarão/RS & 2 & 3 & EMEF Marcílio Dias \\
\hline & & & & EMEF Dr. Fernando Corrêa Ribas \\
\hline & Rio Branco/UY & 2 & 3 & Escuela $\mathrm{N}^{\circ} 05$ \\
\hline & & & & Escuela $N^{\circ} 12$ \\
\hline & Chuí/RS & 1 & 2 & EMEF General Artigas \\
\hline & Chuy/UY & 1 & 2 & $\begin{array}{l}\text { Escuela No } 28 \text { - Republica Federativa } \\
\text { Del Brasil }\end{array}$ \\
\hline \multirow[t]{3}{*}{$\begin{array}{l}\text { Brasil } \\
\text { Venezuela }\end{array}$} & Paracaima & 1 & 4 & EM Alcides da Conceição Lima \\
\hline & $\begin{array}{l}\text { Santa Helena de } \\
\text { Uairén/VE }\end{array}$ & 2 & & EIB San Antonio de Morichal \\
\hline & & & & EIB E1 Salto \\
\hline
\end{tabular}

Total

17

24

107

11 Esta tabela é parte integrante do artigo de Thomaz (2010). 
Ainda em 2009, é noticiado o fato de que Brasil e Uruguai iriam construir escolas técnicas binacionais na fronteira. Pelo projeto, as escolas podem estar em território brasileiro ou uruguaio. Os estudantes, entretanto, devem estar divididos igualmente: metade de brasileiros, metade de uruguaios. Este seria, de acordo com a intenção do Ministério da Educação, um piloto para outros acordos de escolas técnicas de fronteira.

\section{5. $\operatorname{Em} 2010$}

Aprovação de acordo sobre ensino de português e espanhol no Mercosul (PDC-2072/2009). Trata-se de um acordo que estabelece regras para o ensino de português e espanhol como línguas estrangeiras nos países do Mercosul (Brasil, Argentina, Uruguai e Paraguai), aprovado pela Comissão de Constituição e Justiça e de Cidadania (CCJ), em março de 2010.

Segundo o acordo, cada país deverá credenciar uma rede de instituições para a capacitação de professores com cursos de duração mínima de 3 anos e 2.400 horas de estudo. O reconhecimento oficial do título garante que não haverá distinção entre professores de nacionalidades diferentes. $\mathrm{Ou}$ seja, não poderão ser exigidas de professores de outros países do Mercosul quaisquer requisitos para o exercício da docência que não sejam aqueles já exigidos para os seus cidadãos. $\mathrm{O}$ acordo também estabelece que o credenciamento para o ensino de português e espanhol como línguas estrangeiras não permite a docência de qualquer outra disciplina.

Mais uma ampliação do Programa Escola Bilíngue de Fronteira com o ingresso das escolas brasileiras - Pedro Afonso Pereira Goldoni e Professora Geni Marques Magalhães, ambas de Ponta Porã-MS - e das escolas paraguaias - Capitan Pedro Juan Caballero e San Afonso, da cidade de Pedro Juan Caballero. Cada escola entra na experiência com três turmas do primeiro ao terceiro ano do ensino fundamental.

\subsection{Em 2011}

Declaração Conjunta entre Brasil e Argentina sobre cooperação entre os dois países, incluindo a temática da cooperação educacional. A declaração 
trata da necessidade de fortalecer mecanismos de cooperação visando a formação de professores de português e espanhol. Além disso, o documento prevê a ampliação da promoção de mobilidade acadêmica de estudantes e professores universitários de graduação e pós-graduação, por meio de programas de intercâmbio.

Tendo em vista o exposto, incluímos abaixo uma versão adaptada de um mapa - apresentado originalmente na Revista Lingua Portuguesa - que ilustra algumas das medidas adotadas para o ensino do português do Brasil no âmbito do Mercosul.

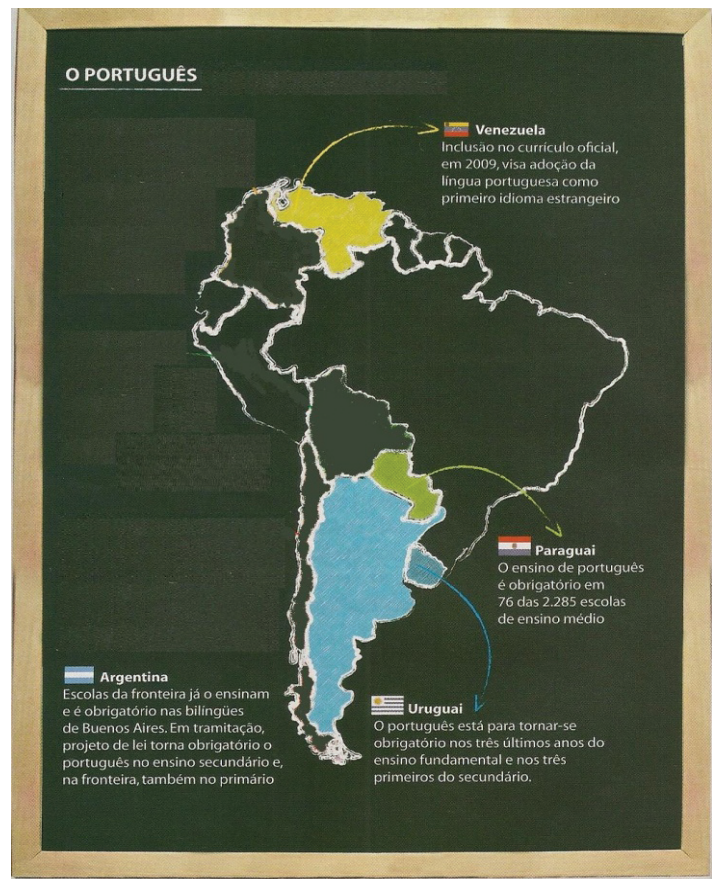

Figura 3: Medidas adotadas para o ensino do português do Brasil no âmbito do Mercosul ${ }^{12}$

Tendo em vista as medidas tomadas, sobretudo nos últimos cinco anos, verificamos que estão na pauta para discussão e em processo de implantação

12 Fonte da ilustração: Adaptada de Revista Lingua Portuguesa, a. 3, n. 32, jun. 2008. 
propostas que objetivam fomentar a difusão do português do Brasil e da cultura brasileira no Mercosul. A fim de tornar o panorama mais amplo e de fornecer dados que possam servir de base para a elaboração de ações futuras com foco no ensino de português língua estrangeira, apresentamos, na sequência, dados que informam sobre os grupos de demanda com maior representatividade.

\section{Demanda para ensino-aprendizagem do português no Mercosul}

Com relação ao outro aspecto sugerido neste estudo, a saber: identificar grupos de demanda para ensino-aprendizagem do português, considerando, sobretudo, o contexto do Mercosul, verificamos a existência de um interesse na aprendizagem de nosso idioma por razões acadêmicas e trabalhistas. Tendo isso em vista, trazemos para este estudo um levantamento das autorizações concedidas para estudo e trabalho a cidadãos de países que compõem o Mercosul com o intuito de verificar em que medida o Brasil funciona de fato como um país receptor de estudantes e trabalhadores oriundos dos países participantes do bloco. $\mathrm{O}$ levantamento a ser apresentado foi realizado a partir de dados fornecidos pela Polícia Federal e pelo Ministério do Trabalho e Emprego, considerando o período 2005-2010.

No que diz respeito a autorizações concedidas para estudo a cidadãos de países participantes do Mercosul - referentes ao período de 2005 a 2010 (até junho) - os dados fornecidos pela Polícia Federal revelam que 6\% de todos aqueles que realizaram estudos no Brasil eram provenientes de países integrantes do bloco (cf. Figura 4). Isso significa que há, ainda, um potencial para crescimento nos próximos anos que não pode ser desprezado. 


\section{Autoriz ações concedidas para estudo no Brasil de 2005 a 2010}

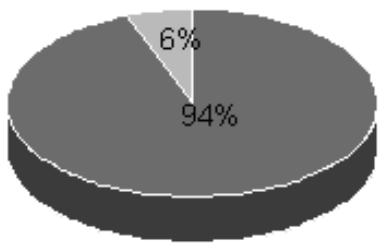

Demais países

Países do Mercosul

Figura 4: Autorizações concedidas para estudo no Brasil - período 2005 a 2010

O gráfico apresentado na Figura 5 expressa, em números, o total de estudantes distribuído (1) por ano e (2) por país de origem.

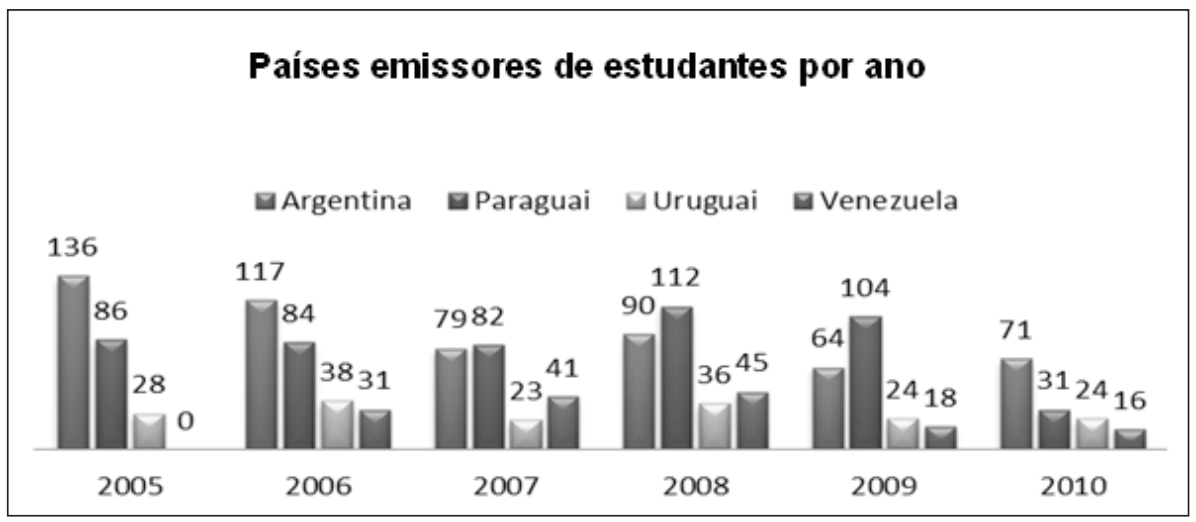

Figura 5: Autorizações concedidas para estudo no Brasil ${ }^{13}$

Conforme podemos observar, a Argentina e o Paraguai foram os países que mais enviaram estudantes no período investigado.

Outra questão de interesse para o nosso estudo é saber em que regiões do Brasil se concentram os estudantes provenientes dos países do Mercosul. Na figura 6, é possível, então, verificar o percentual por regiões do Brasil no período de 2005 a 2010.

13 No ano de 2005, a Venezuela não foi considerada para efeito de contagem, pois ainda não integrava o bloco. 


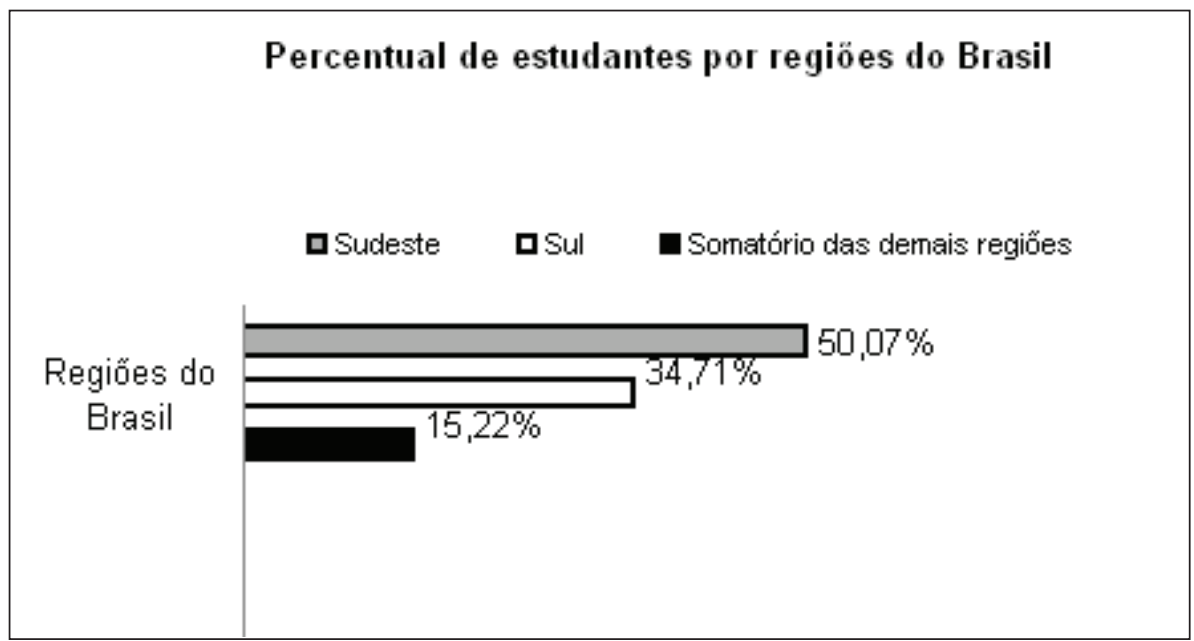

Figura 6: Regiões do Brasil com percentuais mais significativos para o acolhimento de estudantes

Os dados analisados indicam uma clara predominância da região Sudeste para o acolhimento dos estudantes provenientes do bloco, sendo São Paulo o estado dessa região que recebe o maior contingente de estudantes. A região Sul vem logo após a região Sudeste, com predomínio dos estados do Rio Grande do Sul e do Paraná. As demais regiões do Brasil recebem, então, um percentual menos expressivo de estudantes.

Quanto aos dados do Ministério do Trabalho, também relativos ao período de 2005 a 2010, observamos que este - o trabalho - é uma finalidade que faz chegar ao Brasil um número de cidadãos do Mercosul que não pode ser desprezado. Estes - ao lado daqueles que vêm ao Brasil com a finalidade de realizar seus estudos integralmente ou parcialmente - devem ser vistos como potenciais interessados no aprendizado do português. Dessa forma, observamos, na Figura 7, os totais de trabalhadores provenientes de países do Mercosul categorizados por país de origem e ano de entrada no Brasil. 


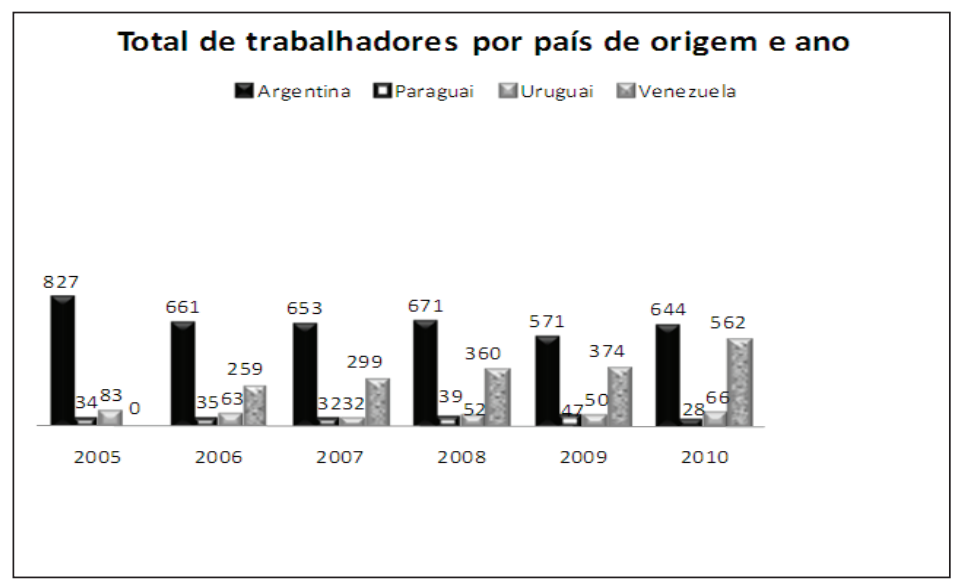

Figura 7: Autorizações concedidas para trabalho no Brasil ${ }^{14}$

No tocante a autorizações concedidas para trabalho, percebemos que a Argentina e a Venezuela foram os países que mais enviaram trabalhadores no período em questão.

Ainda, como questão de interesse para o nosso estudo e futuro cotejamento de dados, apresentamos, tal como foi feito anteriormente para os dados concedidos para estudo, um gráfico ilustrativo das regiões do Brasil onde se concentram os trabalhadores provenientes dos países do Mercosul.

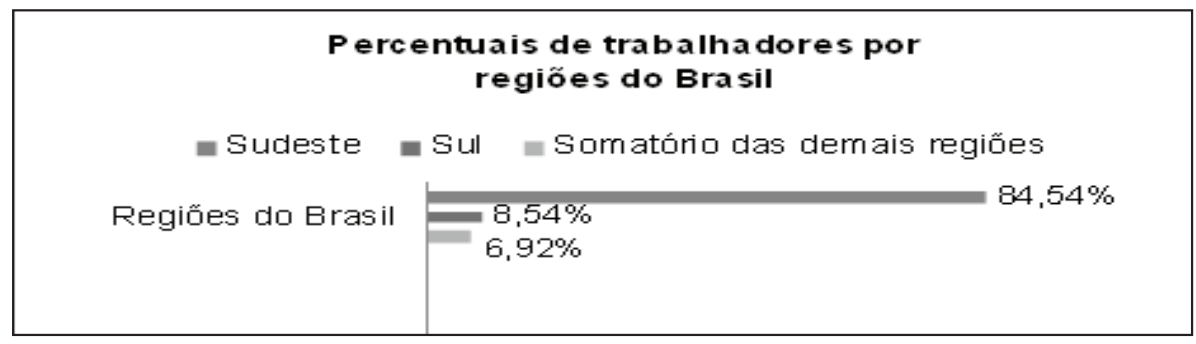

Figura 8: Trabalhadores por regiões do Brasil com percentuais mais significativos

14 No ano de 2005, a Venezuela não foi considerada para efeito de contagem, pois ainda não integrava o bloco. 
No que tange à questão de concessão de autorização para trabalho fornecida pelo Ministério do Trabalho e Emprego, observamos, assim como nos dados relativos ao estudo, que há uma predominância da região Sudeste, seguida pela região Sul, para o acolhimento de trabalhadores estrangeiros. No entanto, nos chama a atenção o valor expressivo desses na região Sudeste.

Em busca de uma visão mais apurada dos dados já expostos, a Figura 9 traz um mapa com a distribuição, por região, dos percentuais das autorizações concedidas para trabalho e estudo.

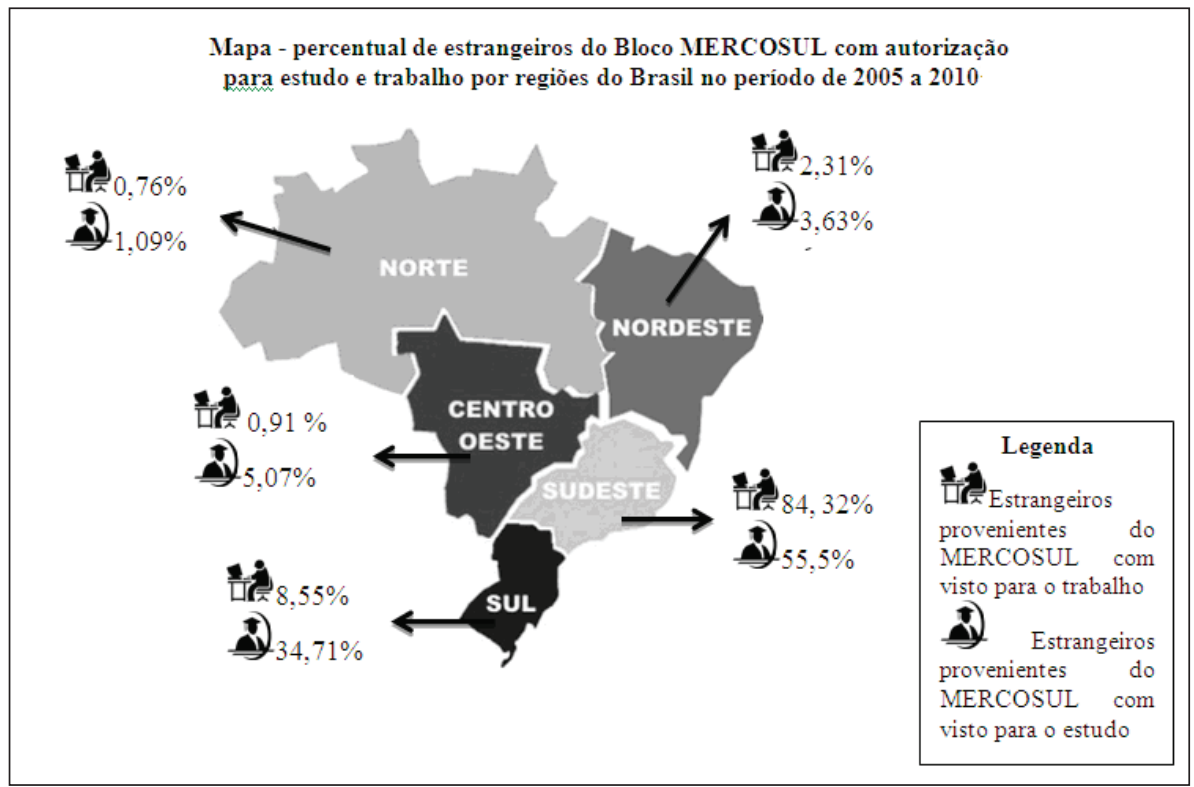

Figura 9: Percentual de estrangeiros do Mercosul com autorização para estudo e trabalho

Ao cotejarmos os dados relativos ao estudo e ao trabalho, constatamos que a região Sudeste, tal como visto, é o destino que recebe mais estrangeiros. Ressaltamos, ainda, que São Paulo e Rio de Janeiro são os estados que mais concedem autorizações aos estrangeiros nas situações descritas acima. Tanto para categoria estudo como para a categoria trabalho, a região Sul 
está sempre em segunda posição.

A proximidade entre a região Sul e países como a Argentina, o Uruguai e o Paraguai poderia nos levar a acreditar que essa região seria preferida para a realização de trabalho e/ou estudo. A partir dos dados apresentados, fica claro que a região Sudeste - apesar de mais distante geograficamente tem conseguido atrair profissionais de diversas áreas, bem como estudantes interessados em desenvolver seus estudos.

Os dados sinalizam, ainda, a necessidade de mais investimentos em outras regiões do Brasil para que estas se tornem também centro de interesse para desenvolvimento, sobretudo, de trabalho e estudo.

\section{Perspectivas Futuras}

Por ocasião da primeira versão deste estudo - realizada, conforme dito, há uma década - já se falava, com relação aos encaminhamentos propostos no âmbito do Mercosul, que o conhecimento dos idiomas de nações circunvizinhas e daquelas com as quais grandes laços comerciais são estabelecidos era de extrema relevância para o sucesso da cooperação técnico-econômica e política tanto entre as organizações envolvidas como para os governos e os povos em si. Verificava-se, igualmente há uma década, o crescente interesse das organizações dos países do Mercosul em atuar no país e estabelecer acordos de parceria com empresas brasileiras. $\mathrm{Na}$ ocasião em que foi apresentada a primeira versão da pesquisa, estudos tinham sido iniciados para viabilizar, por exemplo, uma efetiva integração dos céus da América do Sul, tendo como base o Acordo Fortaleza, envolvendo o Transporte Aéreo Sub-Regional entre o Brasil, Argentina, Chile, Uruguai, Paraguai e Bolívia. Dessa forma, o ensino de português tornava-se, já nessa época, um ponto vital para o sucesso das relações comerciais, culturais e políticas do Brasil para com os países vizinhos.

Em síntese, verificamos, no período coberto por este trabalho, que há, no presente, propostas claras que indicam o papel estratégico desempenhado pela educação e pelo aprendizado do português pelos parceiros do 
Mercosul. No processo de integração, para alcançar o desenvolvimento econômico, social, científico-tecnológico e cultural da região não se pode mesmo deixar de lado as questões que envolvem a língua. Os dados analisados revelam também a importância que tem o Brasil como país que acolhe interessados em desenvolver estudos e atividades relacionadas ao trabalho. Todos os aspectos, é claro, estão intimamente relacionados com o desenvolvimento da área de português língua estrangeira. Nesse momento, é preciso fundamentalmente planejar o futuro. Apesar de todos os avanços, observamos, ainda (tal como há uma década), a necessidade de investimentos mais maciços em formação docente e pesquisas, além de incentivos para e publicações teóricas e de materiais didáticos que se destinem a esse mercado que dá evidentes sinais de expansão.

\section{Referências}

A ECONOMIA BRASILEIRA - Indicadores econômicos gerais. Disponível em: <http://www.economiabr.com.br/Ind/Ind_gerais. htm\#PIB-PPP>. Acesso em: 10 mar. 2011.

ALMEIDA, Patricia M. C.; ESPÍRITO SANTO JR., Respício A. Ensino de português como segunda lingua para os parceiros do MERCOSUL, 2000. (mimeo.)

BELFORT DUARTE, Andrea L. O ensino de PBE no mundo dos negócios: gêneros textuais e escrita. 2009. Dissertação (Mestrado em Letras) Instituto de Letras, Universidade Federal Fluminense, Niterói, 2009.

BRASIL e Uruguai implantarão escola técnica na fronteira. Portal MEC, Brasília, 25 ago. 2009. Disponível em: <http://portal.mec.gov.br/index. php?option=com_content\&view=article $\& i d=14186$ : brasil-e-uruguai implantarao-escola-tecnica-na-fronteira\&catid=209\&Itemid=86>. Acesso em: 27 jan. 2010.

BRASIL. Câmara dos Deputados. PDC 2072/2009. Disponível em: <http://www.camara.gov.br/proposicoesWeb/fichadetramitacao?idProposi 
cao $=457980>$. Acesso em: 20 jan. 2011.

BRASIL. MARCA - Programa de Mobilidade Acadêmica Regional para os Cursos Acreditados pelo Mecanismo de Acreditação de Cursos de Graduação do Mercosul. Disponível em: < http://programamarca.siu.edu. ar/index_portugues.php>. Acesso em: 10 jan. 2011.

BRASIL. Mercosul Educacional. Disponível em: <http://www.sic.inep. gov.br/index.php?option=com_content $\& v i e w=$ frontpage $\&$ Itemid $=1>$. Acesso em: 15 jan. 2011.

BRASIL. Ministério da Educação. Secretaria de Educação Básica. Escolas de Fronteira. Brasília, DF, 2008. Disponível em: <http://portal.mec.gov.br/ seb/arquivos/pdf/Escolafronteiras/doc_final.pdf>. Acesso em: 27 jan. 2011.

BRASIL. Ministério das Relações Exteriores. Cartilha do cidadão do Mercosul 2010. Disponível em: <www.mercosul.gov.br>. Acesso em: 20 jan. 2011.

BRASIL. Ministério das Relações Exteriores. Mercosul. Disponível em: <http://www.mercosul.gov.br/>. Acesso em: 20 jan. 2011.

BRASIL. Ministério do Trabalho e Emprego. Dados completos do balanço do Cgig. Disponível em: <http://portal.mte.gov.br/imprensa/autorizacoespara-estrangeiros-trabalharem-no-brasil-crescem-30-em-2010.htm >. Acesso em: 15 mar. 2011.

BRASIL. Portal da Capes. Programa de parcerias universitárias de graduação em lingua espanhola e portuguesa no Mercosul. Disponível em: <http://www. capes.gov.br/cooperacao-internacional/multinacional/mercosul/parceriasuniversitarias-portugues-espanhol>. Acesso em: 17 mar. 2011.

BRASIL. Programa Executivo Educacional entre o Governo da República Federativa do Brasil e o Governo da República do Paraguai. 12 de abril de 2007. Disponível em: <http://www2.mre.gov.br/dai/b_parg_206_4399. htm>. Acesso em: 27 fev. 2011.

BRASIL. Protocolo entre o Ministério da Educação, Ciência e Tecnologia da República Argentina e o Ministério de Educação da República Federativa do Brasil para a Promoção do Ensino do Espanhol e do Português como Segundas 
Linguas, 30 de novembro de 2005. Disponível em: <http://www2.mre.gov. br/dai/b argt 413 5650.htm >. Acesso em: 27 fev. 2011

BRASIL. Tratado de Assunção. Assinado em 26 de março de 1991 pelos quatro Estados Partes - a República Argentina, a República Federativa do Brasil, a República do Paraguai e a República Oriental do Uruguai. Disponível em: <http://www.mre.gov.br/portugues/politica_externa/ discursos/>. Acesso em: 22 jan. 2011.

DOCUMENTO assinado entre Brasil e Argentina reforça ações da Capes. Capes, Brasília, 8 fev. 2011. Disponível em: <http://www.capes.gov.br/ servicos/sala-de-imprensa/36-noticias/4395-documento-assinado-entrebrasil-e-argentina-reforca-acoes-da-capes >. Acesso em: 27 jan. 2011.

ESCOLA de Fronteira. Portal MEC, Brasília. Disponível em: <http:// portal.mec.gov.br/index.php?option $=$ com_content\&view=article\&id=1 2586: escola-de-fronteira\&catid=341:escola-de-fronteira\&Itemid=835 > Acesso em: 27 jan. 2011.

MERCOSUL. Estrutura Econômica. Disponível em: <http://www. classificadosmercosul.com.br/mercosul_atual.htm>.Acesso em: 10 mar. 2011. MERCOSUR. Secretaria do Mercosul. Disponível em: <http://www. mercosur.int/show? contentid=10\&channel=secretaria $>$. Acesso em: 15 jan. 2011.

NATALI, Adriana. O Brasil flerta com a vizinhança. Revista Lingua Portuguesa, São Paulo, a. 3, n. 32, p. 30-33, jun. 2008.

QUATRO novas instituições vão compor o Escolas de Fronteira. Portal MEC, Brasília, 13 maio 2010. Disponível em: <http://portal.mec.gov.br/ index.php?option=com_content\&view=article\&id=15424:quatro-novasinstituicoes-vao-compor-o-escolas-de-fronteira\&catid=211\&Itemid=86>. Acesso em: 27 jan. 2010

SEVERINO, Antônio J. Metodologia do trabalho científico. São Paulo: Cortez, 2007. 
THE ECONOMIST. Go south, young scientist. Disponível em: <http:// www.economist.com/node/17851421 >. Acesso em: 27 fev. 2011.

THOMAZ, Karina M. A política linguística do projeto escolas interculturais bilíngues de fronteira do Mercosul: ensino de segunda língua para as áreas fronteiriças. Revista Linguas E̊ Letras, Paraná, v. 11, n. 21, $2^{\circ}$ semestre de 2010.

URUGUAI ensinará português em escolas públicas a partir de 2010. Estadão, São Paulo, 22 abr. 2009. Disponível em: <http://www.estadao. com.br/noticias/geral,uruguai-ensinara-portugues-nas-escolas-publicasa-partir-de-2010,358706,0.htm>. Acesso em: 27 jan. 2011. 